\title{
Organizational Leadership Designed at Ensuring Employee Commitment
}

\author{
Cristian-Liviu Vele, $\mathrm{PhD}$ \\ Technical University of Cluj Napoca \\ North University Center in Baia Mare \\ cristian.vele@cunbm.utcluj.ro
}

\begin{abstract}
Every organization wants and need employees that perform at their best in each and every aspect of their work. This, in terms, leads to an increase in organizational efficiency and to the development of competitive advantages in relationship with other competitors. But how can organizations develop a working environment in which employees give their full commitment to organizational strategic goals? What are the cultural elements that drive people to develop the necessary beliefs and behaviors in order to fully commit to an organization? In what manner does the leadership of an organization contribute to the increase of individual commitment? The main objective of this article is to identify and analyze possible correlations between certain elements of transformational leadership and employee commitment. One of the main challenges that companies face in present times is the constant shift in the business environment that requires a high level of flexibility and adaptation. Given the fact that employees are the company's front line by coming in contact with customers, it is paramount that their behavior and commitment is focused on providing the highest value for the market. For this reason, managers need to fully understand how to motivate individuals in order to become completely involved in their work and in offering their contribution to organizational success. The findings presented in the paper can help managers and leaders in their efforts to retain employees and to increase their involvement in the long term sustainable development of the organization in which they work. KEYWORDS: Leadership, organizational change, creativity, strategy, competitive advantage
\end{abstract}




\section{Introduction}

The $21^{\text {st }}$ century saw a shift in leadership and organizational culture towards results and customers, rather that internal processes and procedures. Also, organizations found themselves in a position to quickly adapt to environmental changes, to take higher risks and to focus in increasing their innovation. When referring to employees, everyone needs to solve problems and everyone needs to be an active part of the strategic thinking and leading process. Also, knowledge workers and project - based employment have created multiple interdependencies between individuals and changed the manner in which performance systems are designed. As a consequence, everyone needs to be a leader, to coach others and delegate responsibility, to encourage teamwork and team rewards, to do the right thing and to take appropriate risks (Hiebert and Klatt 2001,2). We are living in a new creative age, where businesses need to adapt to constant changes and where creative and innovative employees are not the exception but rather a necessity in order to gain and maintain competitive advantages. Here leaders and managers play a crucial role, not only in attracting creative individuals that have an out - of - the box thinking, but rather in creating and fostering a culture that encourages people to use their abilities in order to find the most efficient solutions to problems according to the particularities of each situation. We need to agree that a solution that has work well enough before will become useless if the same problem arises again, simply due to the fact that the environment changed drastically.

The use of social media in advertising or the increase in e-commerce and secure e payment have made it possible for companies to access a virtually global market. But this opportunity generated many organizational problems, like understanding the differences between what customers want in different markets and how to increase the speed in which an organization offers for sale a product or service. This is where leadership plays a crucial role in ensuring that each and every employee will work together towards a common purpose and become committed to organizational long term success. It was discovered that employee commitment (Hiebert and Klatt, 2001) occurs in working environments that sustain motivation, teamwork and accountability. These kind of working environments are characterized by a high degree of inclusion, where individuals are recognized for their work, are involved and accepted, by a control influenced by great personal responsibility and by affection, respect and support from other members in the group. 


\section{Some theoretical considerations on leadership and organizational change}

According to the European Foundation for Quality Management (EFQM) the leaders of an organization must create clarity and unity of purpose within the organization and to help establish an environment in which people can excel. In an organization, leaders do the right things and managers do the things right (Morden 2007,331). According to Warren Bennis and Robert Thomas's leadership model (2002), leaders are shaped by individual factors and organizational environment, along with experience. As a consequence certain key competencies leadership form, like adaptive capacity, engaging others by creating shared meaning, voice and integrity. Leaders have shown excellent attention in noticing opportunities or changes in the business environment and to proactively seize the opportunities. Also, they show great creativity and willingness to constantly learn. By using their self-confidence and emotional intelligence, along with empathy for others, leaders are able to form and communicate purpose for other. This motivates individuals to actively use their abilities and competencies in order to be a part of the organization's success and development.

Kouzes and Posner (2002) analyzed over 75.000 responses from individuals and compiled a list of leadership skills: ambitious, broad-minded, caring, co-operative, competent, courageous, dependable, determined, fair-minded, forward-looking, honest, imaginative, independent, inspiring, intelligence, loyal, mature, self-controlled, straightforward, and supportive.

When it comes to long term sustainable organizational development, leadership is a key issue in developing and focusing individual interest towards core values, culture and ideology. But in order to ensure the success of new strategies, leaders need to conduct changes within their organization and to synchronize organizational objectives with the ones of employees. Although managing cultural change is not an easy task, it is not entirely impossible to get people involved in new strategic objectives or even in new strategic directions. There are many factors influencing the change process, but the most important is the strength of the current culture and the size of the proposed change (Hannagan 2002, 157).

Edgar Schein (2004) describes culture as: A pattern of shared basic assumptions that the group learned as it solved its problems of external adaptation and internal integration that has worked well enough to be considered valid and, therefore, to be taught to new members as the correct way you perceive, think, and feel in relation to those problems. 
For organizations, culture represents the "way we do things around here" (Morden 2004) and has a crucial influence over managers and their leadership style. By protecting the organization's ideology and values, the culture is protected on long term and communicated at every level. Also, a major outcome of organizational culture is the expectation of commitment and loyalty from employees (Morden 2007, 385). Components of culture, such as prevailing values systems, expected standards of behavior or the perception of strategic, managerial and operational necessity contribute to the expectations that individuals will likely develop a common sense of commitment and loyalty towards the organization's strategic aims and that they will work as a team to ensure the success of these aims. Equally, the process of internal promotion to higher organizational levels may be formulated and implemented based on the history of each individual within the organization and also on their past involvement in shaping, guarding and promoting the values, objectives and strategy of the organization. Thus, one key aspect of the promotion process becomes the involvement and commitment of individuals (Boca et al. 2016).

Ensuring the employee commitment implies shifting responsibility from managers to each individual within the organization. This does not mean that managers run from their specific responsibilities, but rather sharing responsibility with others. Managers and leaders need to plan in advance and organize people and activities in such a manner in which the strategic goals of the planning process are successfully met. A key element in ensuring this success is to actively implicate employees in the strategic process, mainly those that are in the front line of an organization. These individuals can be a valuable source of competitive advantage by flexibly and rapidly respond and adapt to changes in customers' behavior and needs. Empowerment offer individuals meaning and purpose in their work, letting them to choose how to do their work and to set their own personal objectives. By letting them to take control over their work, leaders show employees that their work have a great impact over the organization and that the outcomes of their work actively contribute to the overall success. Not last, empowering individuals and letting them to organize their work, can lead to an efficient use of their personal skills and capabilities, while boosting their self-confidence (Clutterbuck 1995; Thomas and Velthaus 1990).

Studies performed by Louis Carter (2005) have revealed that employees are more authentic and have a greater desire to be a part of an organization that anticipates learning opportunities and, in some organizations, individuals consider that creativity and innovation in everyday activities need to become a necessary requirement. Innovation needs to be modeled by leaders throughout the organization, some companies even design their programs around their leaders' behavior and values 
in order to ensure maximum support. The best practice systems in organizational leadership orientated towards the constant development of individuals are designed and implemented with a full understanding of the particularities of organizational culture and of the social system. Also, everybody in the organization, starting with its leaders show an uncontested belief in these programs and practices, and participate in a constant assessment of the programs especially from a financial point of view, given the fact that the ultimate objective is to create a leadership model that increases profitability and actively participate to achieving the organization's strategic objective. Managers need to set, as a strategic objective, a full commitment from employees towards organizational success and development. In order to achieve this commitment they should transmit a clear vision that is backed up by a clear strategy and strategic goals and also to coach, mentor and support people to achieve their best, without expecting people to get it right every time. Also, work should be organized in projects and teams, in order to get people to communicate and solve problems together, but increasing the chances to get the best decisions and actions to implement these decisions. Even more, by working in teams, a high level of individual participation in ensured while allowing people to decide how to do their work. Generating commitment from employees is not a one-time action, but rather a long-term constant investment with the purpose of creating and sustaining a high level of energy and passion that people bring to work.

To achieve this managers need to design and support an organizational culture in which commitment becomes more than an obligation becomes a magnet for people that perform efficient in such an environment and which are able to promote such environment to others. The first step is to create trust within the organizations without trust commitment simply cannot exist. Trust resides in how individuals think that others will protect and act in their best interest. In a trusted environment, you truly believe that your colleagues and/or managers will work in your best interest and you can count on them to do what's right, whether you are there to see it or not (Church \& Oliver 2006, Hahn et al., 2012). Trust becomes even more important when people face ambiguity or uncertainty, thus becoming vulnerable. When certain events cause distress for employees they become distracted from work and star worrying for their personal future. This is the moment when trust is most valuable, by freeing individuals from such worries and channeling their full energy and commitment to work. Organizations require employees to invest their time, expertise, talent and energy into efficient organizational development, but in order to achieve this people need to know that they are doing a wise decision. When trust is present, employees do not feel the need to protect themselves and are confident that others, including the 
management, will protect them and thus will channel all their efforts and capabilities toward the organization's best interest (Macey et al. 2009, 46-48).

Based on Schein's model (2004), in order to create a culture in which employees are fully committed to the strategic organizational goals, managers must pay attention to, monitor and measure the degree in which the entire organization values or devalues individuals. The human capital can be valued by showing concern and support for their health or even personal problems, or by emphasizing the importance of loyalty and of the fact that employees are not just a simple resource that can be disposed of overnight. Secondly, managers need to allocate resources in such a manner in which employees increase their commitment, by designing their jobs in accordance with their skills and abilities, by offering them training, by formulating specific goals and by offering positive feedback and reward for their accomplishments. Finally, the work systems and procedures need to be designed together with house affected then and need to ensure the fair treatment of everyone within the organization.

As stated before, ensuring employee commitment is a continuous process that needs to be supported and updated on a constant basis. The mechanism behind supporting a culture of employee commitment requires a relatively flat organizational design in which individuals can be empowered and involved in the future of the organization. Risk taking, creativity and innovative thinking should also be encouraged and rewarded, while communication between individuals regarding their involvement and purpose within the organization is crucial in order to create a sense of belonging.

\section{Empirical research}

The purpose of this article is to analyze, in an empirical manner, the relationships and correlations between organizational leadership and how it influences employee commitment. In order to achieve this, a questionnaire - based research was conducted on over 200 employees and managers, followed by a statistical analysis of the answers that was conducted using specialized software, namely IBM SPSS Statistics. The items in the research questionnaire are related, on one hand, to certain leadership characteristics within the organizations, such as the empowerment of employees, offering support in order to meet specific goals, communication or the support of employee innovative and creative thinking and, on the other hand, are focused on how committed employees are in their work.

Following the results of the statistical analysis it was observed that relevant correlations (the statistical significance coefficient needs to be smaller than 0,01 or 0,05 , dependent 
on the situation) were obtained between understanding and visualizing the end results of one's work and their efficiency and goal orientated behavior. More specifically, the individuals that were part of this study stated that when they understand and are able to see the end result of their activities, they feel more ambitious about their work (the value of the Pearson's linear correlation is 0,431 and the value of the significance coefficient is 0 ) and have a clear desire to increase their efficiency in order to gain the most results (the value of the Pearson's linear correlation is 0,404 and the value of the significance coefficient is 0 ). Another interesting conclusion of the research was that visualizing the results of one's work motivates that person to start working immediately and to be the best in meeting their responsibilities (the value of the Pearson's linear correlation is 0,395 and the value of the significance coefficient is 0 ).

One of the key aspects of this present research was to observe and analyze links between the managers' support for employees and the efficiency and results of employees. The findings have shown that support in overcoming one's limits from managers leads to a higher commitment from employees (the value of the Pearson's linear correlation is 0,403 and the value of the significance coefficient is 0 ) and also leads to an increase in individual ambition and perseverance, respondents declaring that reaching the set goal becomes paramount when the leaders show high implication and support and that failure will only motivate them to work harder (the value of the Pearson's linear correlation is 0,428 and the value of the significance coefficient is 0 ).

The interesting part of the research was to discover that a clear communication, understanding and visualization of organizational objectives by employees leads to an increase in ambition, will to success and overall commitment, all of these leading to a general increase in group efficiency. Managers have declared that working teams became more efficient when characterized by a high level of ambition (the value of the Pearson's linear correlation is 0,442 and the value of the significance coefficient is 0 ), getting maximum result from a particular situation (the value of the Pearson's linear correlation is 0,472 and the value of the significance coefficient is 0 ) and finishing a task, without exception, no matter the difficulties (the value of the Pearson's linear correlation is 0,485 and the value of the significance coefficient is 0 ).

\section{Conclusion}

This article set out to offer a better understanding of the connections between some characteristics of organizational leadership and their influences on employee commitment. As it can be seen in the first part of this article, researchers suggested that employee commitment can be achieved by empowering employees and making them 
a part of the strategic process, especially when it comes to the formulation of strategic objectives. It is true that an increase in employee commitment has the potential to lead to more loyal employees which become fully involved in organizational development and success and ultimately generate more profit. For this reason, managers need to know exactly what are the main elements that have the potential to lead to high commitment from employees.

A key conclusion of the research is that employees become more committed to organizational objectives when they better understand and visualize those objectives. In other words, managers need to make sure that individuals know exactly their destination before they begin to organize the process of getting there. Also, individuals need to understand what are the implications of the result that their will obtain in ensuring the future organizational development. When achieving all of the above, individuals better understand their role and importance within the organization and become more ambitious and focused of getting results no matter the difficulties.

Also, the managers' support plays a crucial role in employee commitment. Individuals need to know that they are not alone in the organization and that they can depend on others to find and implement the best solution to the problems faced in their journey to obtain the desired results. A high support also leads to an increase in perseverance from employees, thus failure is not a valid option. Difficulties in performing one's responsibilities are used as a powerful motivation element and empowering individuals forces them to think creative to find the most efficient solution.

From a theoretical point of view, this article offers a better understanding of how certain particularities of organizational leadership influence employee commitment and even organizational development. But, the main objective is for this article to be used as a practical tool by managers in order to increase employee commitment and active involvement in the organization. Every manager, every leader needs to know that they can depend on their team on the road to success, but loyalty an involvement are not elements to be taken for granted and ensuring employee commitment is a constant process. Thus, organizations need to create a culture in which employees are treated, not as mere resource, but rather as decisive factors in formulating and implementing the competitive strategy that will generate increase value in relation with the competition. 


\section{References}

Bennis, Earren G., and Robert J. Thomas. 2002. Geeks E Geezers: How Era, Values, and Defining Moments Shape Leaders. Boston, Massachusetts: Harvard Business School Press.

Boca, Gratiela Dana, Lindita Mukaj, and Marsida Vishkurti. 2016."Creating a model culture of management change." Annals of Faculty of Economics 25, no. 25: 871-880. University of Oradea, Faculty of Economics.

Carter, Louis, David Ulrich, and Marshall Goldsmith. 2005. Best Practices in Leadership Development and Organization Change. San Francisco, CA: Pfeiffer.

Church, A. H., and D. H. Oliver. 2006. "The importance of taking action, not just sharing survey feedback." In A. Kraut (Ed.), Getting action from organizational surveys: New concepts, technologies, and applications, 102-130. San Francisco: Jossey-Bass.

Clutterbuck, D. 1995. The power of empowerment. London, UK: Kogan Page.

Hahn, Rada-Florina, Simona Sabou, Rita-Monica Toader, and Corina Michaela Radulescu. 2012."About emotional intelligence and leadership." Annals of Faculty of Economics 1, no. 2: 744-749. University of Oradea, Faculty of Economics.

Hannagan, T. 2002. Mastering strategic management. Hampshire, UK: Palgrave.

Hiebert, Murray, and Bruce Klatt. 2001. The Encyclopedia of Leadership. A Practical Guide to Popular Leadership Theories and Practices. New York: McGraw-Hill.

Kouzes, Jim, and Barry Posner. 2002. The Leadership Challenge. San Francisco: Jossey Bass Wiley. Macey, William H., Schneider, Benjamin, Barbera, Karen M., and Young, Scott A., 2009. Employee Engagement: Tools for Analysis, Practice, and Competitive Advantage. Malden, USA: Wiley - Blackwell.

Morden, T. 2007. Principles of strategic management, $3^{\text {rd }}$ ed. Aldershot, UK: Ashgate Publishing Limited.

Schein, Edgar. 2004. Organizational culture and leadership, 3rd ed. San Francisco: Jossey-Bass.

Schein, Edgar. 2004. Organisational Change and Leadership. Pfeiffer Wiley.

Thomas, Kenneth W., and Betty A. Velthouse. 1990. "Cognitive Elements of Empowerment: An "Interpretive" Model of Intrinsic Task Motivation." The Academy of Management Review 15, no. 4 (October): 666-681. 